\title{
Implementasi Sistem Sensor Sederhana untuk Peringatan Banjir melalui SMS
}

\author{
Octarina Nur Samijayani ${ }^{*}$, Fadjar Iftikar, M. Hariomurti, Dwi Astharini \\ Program Studi Teknik Elektro, Fakultas Sains dan Teknologi, \\ Universitas Al Azhar Indonesia, Jl. Sisingamangaraja, Jakarta 12110 \\ "Penulis untuk korespondensi: Octarina.nur@uai.ac.id
}

\begin{abstract}
Abstrak - Menilik pada beberapa masalah yang sering terjadi terutama di kota besar Jakarta, diantaranya banjir, kawasan perumahan di daerah dataran rendah dan berada disekitar sungai besar merupakan daerah rawan banjir. Pengabdian masyarakat berbasis penelitian ini bertujuan untuk menerapkan keilmuan elektronika mengenai instrumentasi dan mikroprosesor yakni sistem sensor air yang didesain untuk mengetahui ketinggian air di sekitar sungai dan saluran air dekat perumahan. Sistem sensor ini bertujuan memberi isyarat akan adanya banjir melalui SMS, sehingga pompa air dapat segera diaktifkan untuk menyedot air agar dialirkan ke sungai. Hasil uji coba laboratorium untuk sistem sensor air dengan prinsip dasar bahwa air sebagai penghantar menggunakan dua pelat konduktor telah berhasil diimplementasikan. Uji coba sistem dengan microcontroller dan GSM Module juga telah berhasil mengirimkan SMS (sebagai alert banjir). Sistem GSM akan mengirimkan SMS jika rangkaian LM339 mengindikasikan bahwa air telah mencapai ketinggian yang berpotensi terjadinya banjir.
\end{abstract}

Abstract - Flood is becoming the main problem especially in Jakarta. The housing area near the river is categorized as the flood-prone areas. This public service research based aims to implement the electronics knowledge especially on instrument and microprocessor system which utilizing the water sensor to indicate the water level around the river and drain. Water sensor is integrated with the GSM module in order to send the flood alert to the society. The laboratory experiment result shows that the water sensor with GSM module has successfully sent the alert when the water level reach the potential level of flood.

Keywords - water sensor, flood early warning system, GSM Module.

\section{PENDAHULUAN}

$\mathrm{K}_{\mathrm{b}}^{\mathrm{a}}$ awasan perumahan di daerah sekitar sungai besar merupakan daerah rawan banjir. Beberapa upaya yang telah dilakukan untuk menanggulangi banjir diantaranya dengan pembangunan tanggul air yang tinggi untuk menahan air sungai agar tidak meluap ke daerah perumahan. Untuk mengatasi banjir akibat meluapnya air dari selokan dapat diupayakan dengan menyedot air dengan menggunakan mesin pemompa. Sejauh ini penggunaan pompa untuk menyedot air ini masih dioperasikan secara manual dan dihidupkan pada saat banjir telah menggenangi rumah warga.

Penelitian berbasis pengabdian masyarakat ini bermaksud untuk mengimplementasikan sistem sensor sederhana untuk memprediksi terjadinya banjir kemudian mengirimkan pesan singkat SMS kepada warga, sebagai peringatan adanya banjir sehingga warga dapat segera menghidupkan mesin pemompa untuk menyedot air segera agar tidak menggenangi rumah penduduk.

\section{KERANGKA TEORI/ TINJAUAN PUSTAKA}

Sensor sederhana yang diimplementasikan adalah menggunakan prinsip dasar elektrolisis [1] yang memanfaatkan sifat air sebagai penghantar listrik yang berfungsi seperti saklar otomatis. Gambar 1 menunjukkan ilustrasi prinsip dasar sensor air yang digunakan.

Sensor sederhana ini diletakkan di ketinggian tertentu dimana apabila air telah mencapai 


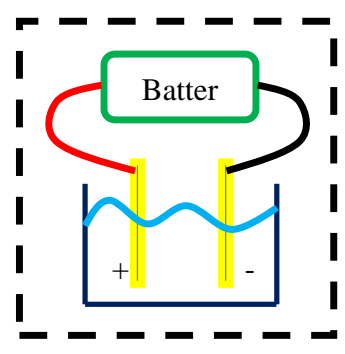

Gambar 1. Prinsip dasar sensor air.

ketinggian ini maka akan berpotensi terjadinya banjir. Sehingga apabila sensor ini telah tergenang air, maka kedua pelat konduktor akan terhubung dan akan terjadi aliran listrik, yang selanjutnya akan menghidupkan switch relay yang kemudian mengaktifkan rangkaian GSM modul.

Sensor sederhana ini banyak dimanfaatkan untuk mendeteksi ketinggian air baik pada satu level tertentu atapun pada beberapa level ketinggian air [2]. Selain dengan memanfaatkan dua pelat sebagai penghantar, sensor sederhana juga dapat dibuat dengan memanfaatkan sensor magnet [3], sensor ultrasonic [4],[5], potensiometer geser [6] dan lain sebagainya. Pada penelitian ini akan digunakan sensor sederhana dengan menggunakan dua pelat konduktor yang dapat menimbulkan resistansi air tanah dalam orde kilo ohm [2].

Jakarta sudah memiliki early warning system banjir dan pemerintah juga terus menyempurnakan sistem peringatan dini terhadap bahaya banjir agar dampak bencana tahunan tersebut bisa dikendalikan dan diminimalkan [7]. Namun belum semua titik rawan banjir di sekitar sungai telah dibangun early warning system. Sistem peringatan dini banjir banyak dikembangkan dengan meningkatkan kecepatan penyampaian informasi banjir, yakni dengan memanfaatkan jaringan GSM melalui SMS untuk memberikan peringatan akan adanya banjir [6], [8], [9], [10].

Pada penelitian ini akan dirancang sistem peringatan dini banjir dengan memanfaatkan sensor sederhana yang diintegrasikan dengan sistem penyampaian informasi/peringatan melalui SMS. Ilustrasi mengenai penerapan sistem sensor terlihat pada Gambar 2.

Sistem sensor diterapkan untuk mendeteksi keadaan berpotensi banjir, yakni berdasarkan ketinggian air di selokan perumahan dan di daerah sungai. Sensor air (S1) dipasang di daerah sungai dan sensor air (S2) di selokan. Kegiatan pengabdian

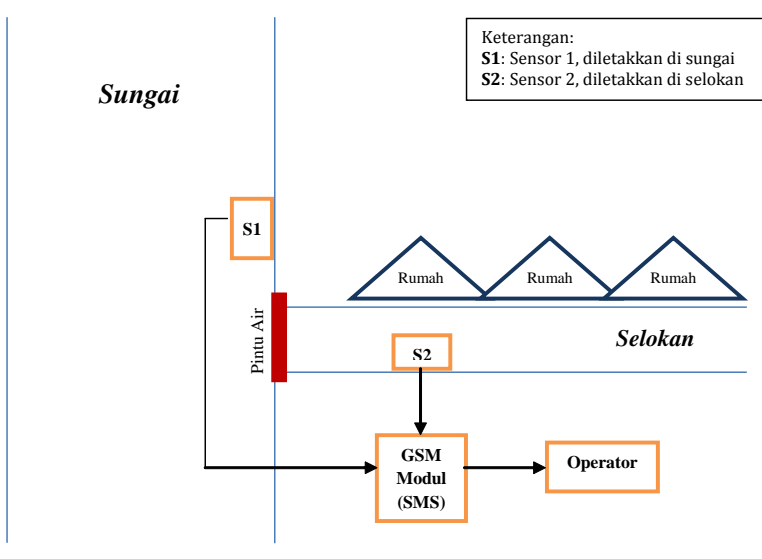

Gambar 2. Sistem Peringatan Banjir dengan SMS

masyarakat ini mengimplementasikan sistem penanggulangan banjir dengan memberikan peringatan melalui SMS. Adapun rancangan sistem peringatan banjir adalah seperti pada Gambar 2.

\section{METODE PENELITIAN}

Penelitian dimulai dengan merancang sensor dengan terlebih dahulu dilakukan observasi untuk mengetahui tingkat ketinggian air yang berpotensi terjadinya banjir, lebar sungai, lebar selokan, jarak antara sungai dengan daerah perumahan, serta parameter lainnya yang diperlukan untuk mendesain sensor. Daerah yang menjadi tujuan kegiatan pengabdian masyarakat ini adalah daerah rawan banjir di sekitar Pondok Aren, Jakarta dan Margahayu, Bekasi. Tingkat banjir di kedua daerah ini sekitar 2-3 kali dalam setahun dengan ketinggian air kurang lebih $50 \mathrm{~cm}$ dari permukaan tanah. Adapun profil kedua daerah penelitian ini dirinci pada Tabel 1 berikut:

Tabel 1. Profil sungai dan saluran air di lokasi penelitian

\begin{tabular}{|c|c|c|c|}
\hline No & $\begin{array}{c}\text { Profil sungai dan } \\
\text { saluran air }\end{array}$ & Daerah I & Daerah II \\
\hline 1 & $\begin{array}{l}\text { Rata - rata } \\
\text { kedalaman sungai }\end{array}$ & $\pm 5 \mathrm{~m}$ & $\pm 1,5 \mathrm{~m}$ \\
\hline 2 & $\begin{array}{l}\text { Rata - rata } \\
\text { kedalaman selokan }\end{array}$ & $\pm 1 \mathrm{~m}$ & $\pm 0,8 \mathrm{~m}$ \\
\hline $\begin{array}{l}3 \\
4\end{array}$ & $\begin{array}{l}\text { Lebar sungai } \\
\text { Lebar selokan }\end{array}$ & $\begin{array}{c} \pm 4 \mathrm{~m} \\
\pm 0,5 \mathrm{~m}\end{array}$ & $\begin{array}{c} \pm 4 \mathrm{~m} \\
\pm 0,5 \mathrm{~m}\end{array}$ \\
\hline 5 & Ukuran pintu air & $\begin{array}{l}\text { Diameter: } \\
\pm 40 \mathrm{~cm}\end{array}$ & $\pm 1 \mathrm{~m}$ \\
\hline 6 & $\begin{array}{l}\text { Jumlah pompa air } \\
\text { dalam satu } \\
\text { kawasan } \\
\text { perumahan }\end{array}$ & $\begin{array}{l}4 \text { buah } \\
\text { pompa }\end{array}$ & $\begin{array}{l}1 \text { buah } \\
\text { pompa }\end{array}$ \\
\hline
\end{tabular}


Untuk sensor ketinggian air, digunakan rancangan sensor dengan pelat konduktor, serta rangkaian LM339 dengan Relay untuk pemroses masukan dari sensor. Sensor berfungsi memberikan isyarat mengenai ketinggian air, selanjutnya rangkaian LM339 dengan Relay memproses masukan dari sensor yang kemudian dapat berfungsi sebagai sistem otomatis yang akan mengaktifkan alarm dan memberikan alert/peringatan melalui pesan singkat SMS. Gambar 3 adalah skema rancangan sensor air.

Sensor sederhana memanfaatkan sifat penghantar dua buah pelat konduktor yaitu apabila terkena air akan mengalirkan arus listrik. Apabila kedua pelat terhubung oleh air yang menandai batas air sudah mencapai ketinggian batas terjadinya banjir, maka rangkaian LM339 akan aktif (teraliri arus) sehingga dapat memberikan perintah untuk mengaktifkan sistem peringatan dengan sms dan mengaktifkan pompa air. Gambar 4 adalah rangkaian LM339 dengan Proteus.

Pada implementasi sistem peringatan banjir, keluaran dari rangkaian LM339 diatas akan menjadi inputan sistem microcontroller dan GSM module yang akan memproses pengiriman pesan singkat SMS. Apabila keluaran dari rangkaian LM339 adalah ON (yang menandakan adanya banjir) maka GSM module akan mengirimkan pesan text "Alert Banjir" pada nomor GSM Handphone operator. Gambar 5 menjelaskan alur sistem GSM module untuk peringatan banjir.

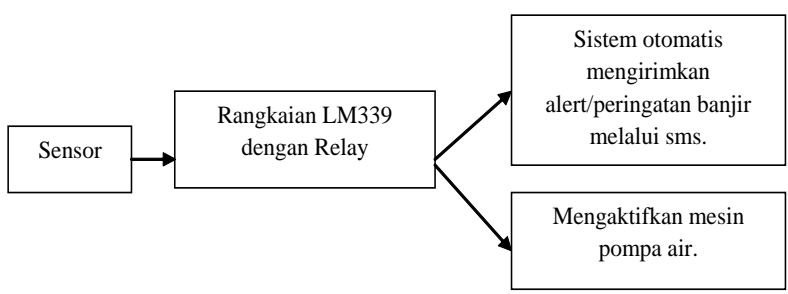

Gambar 3. Skema rancangan sensor air

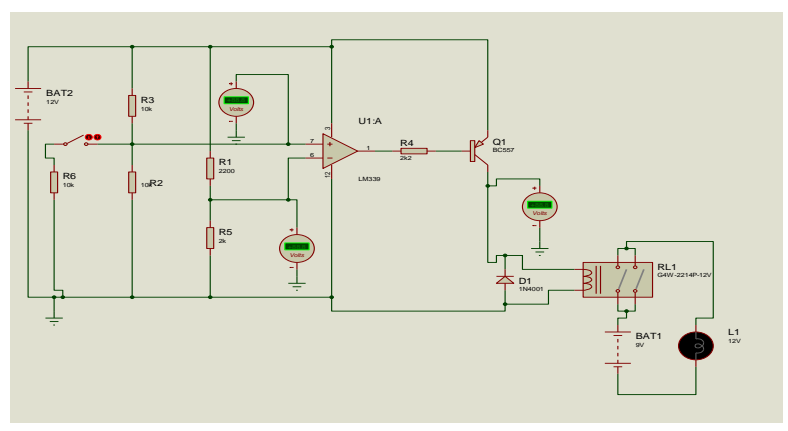

Gambar 4. Rancangan rangkaian dengan LM339 menggunakan Proteus.

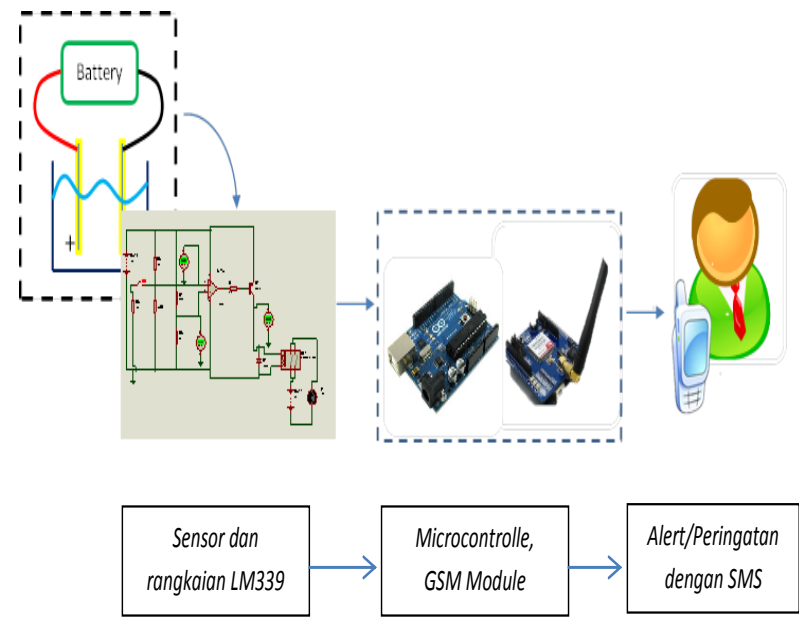

Gambar 5. Aplikasi GSM module untuk peringatan banjir.

\section{HASIL DAN PEMBAHASAN}

Setelah perancangan dengan menggunakan software proteus, rangkaian LM339 diuji coba secara langsung. Uji coba dilakukan untuk mencoba fungsi switch dari rangkaian ini, serta mengetahui berapa daya yang diperlukan sebagai catu daya rangkaian ini. Adapun foto uji coba rancangan rangkaian LM339 adalah pada Gambar 6 , dan skematik rancangan PCB untuk rangkaian LM339 ditunjukkan pada Gambar 7.

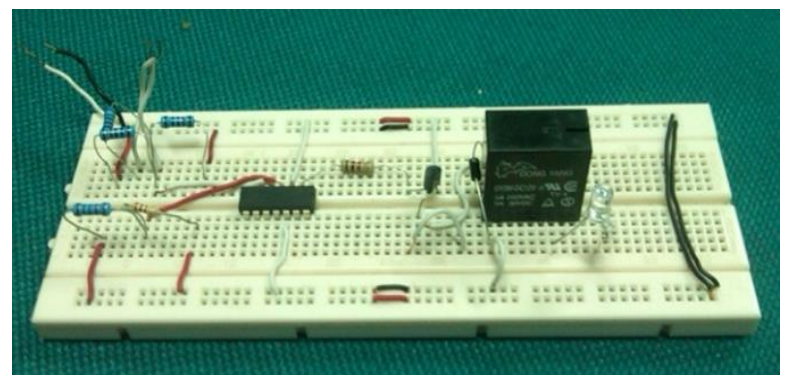

Gambar 6. Uji coba rangkaian LM339.

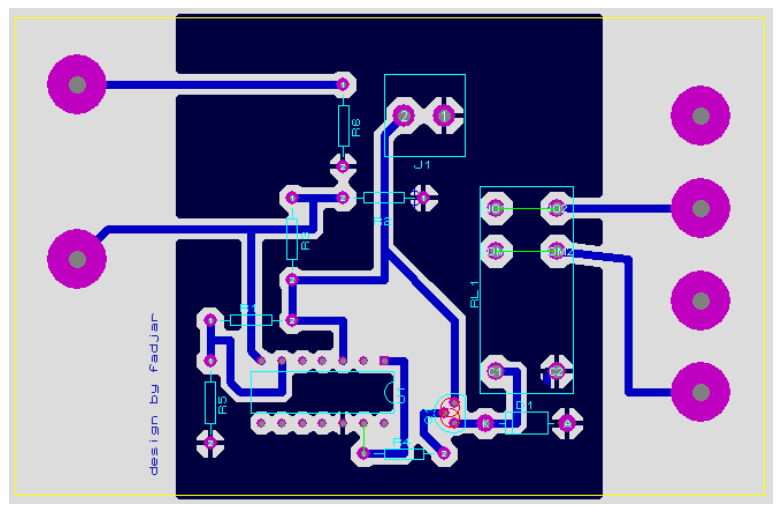

Gambar 7. Desain PCB rangkaian LM339. 


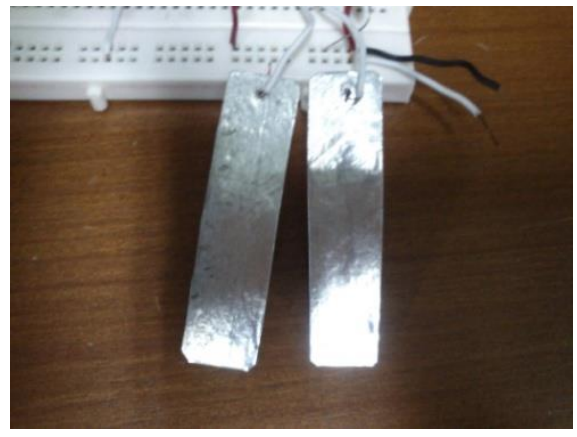

Gambar 8. Pelat Konduktor untuk sensor air.

Uji coba sistem sensor otomatis ini telah menunjukkan hasil yakni, apabila sensor air aktif dan terhubung arus, maka keluaran relay akan mengaktifkan komponen. Sistem otomatis ini bekerja sebagai switching untuk keadaan dimana adanya arus dari sensor atau tidak adanya arus, yang menandakan ketinggian air yang telah mencapai batas indikasi banjir. Adapun pelat konduktor yang digunakan sebagai sensor air sederhana ditunjukkan pada Gambar 8. Untuk tahapan selanjutnya, setelah uji coba laboratorium untuk rancangan sistem sensor ini selesai, akan dilakukan pengemasan paket sistem sensor ini agar dapat diletakkan secara aman di sekitar sungai dan di sekitar selokan air.

Untuk memproses masukan dari sensor, digunakan microcontroller dan GSM shield yang akan mengirimkan SMS kepada operator apabila ketinggian air sudah mencapai batas terjadinya banjir. Pesan yang akan dikirimkan adalah "Alert Banjir" "Ketinggian Air mencapai batas potensi banjir". Adapun microcontroller yang digunakan adalah ATmega328 dengan spesifikasi dan fitur dapat dilihat pada tabel 2.

Tabel 2. Spesifikasi ATmega328 dan Fitur GSM Shield

\begin{tabular}{|c|c|}
\hline Alat & Spesifikasi dan Fitur \\
\hline \multirow[t]{4}{*}{ ATmega328 } & Input voltage - 7-12V, 14 Digital I/O \\
\hline & Pins (6 PWM outputs), 6 Analog \\
\hline & Inputs, 32k Flash Memory, $16 \mathrm{Mhz}$ \\
\hline & Clock Speed. \\
\hline \multirow[t]{9}{*}{ GSM Shield } & Quad-Band 850/ 900/ 1800/ $1900 \mathrm{MHz}$, \\
\hline & GPRS multi-slot class 10/8, GPRS \\
\hline & Compliant to GSM phase $2 / 2+$, Class 4 \\
\hline & (2 W @ 850/ 900 MHz), Class 1 (1 W \\
\hline & @ 1800/1900MHz), Control via AT \\
\hline & commands and SIMCOM enhanced AT \\
\hline & Commands), Low power consumption: \\
\hline & 1.5mA (sleep mode), Operation \\
\hline & temperature: $-40^{\circ} \mathrm{C}$ to $+85^{\circ} \mathrm{C}$ \\
\hline
\end{tabular}

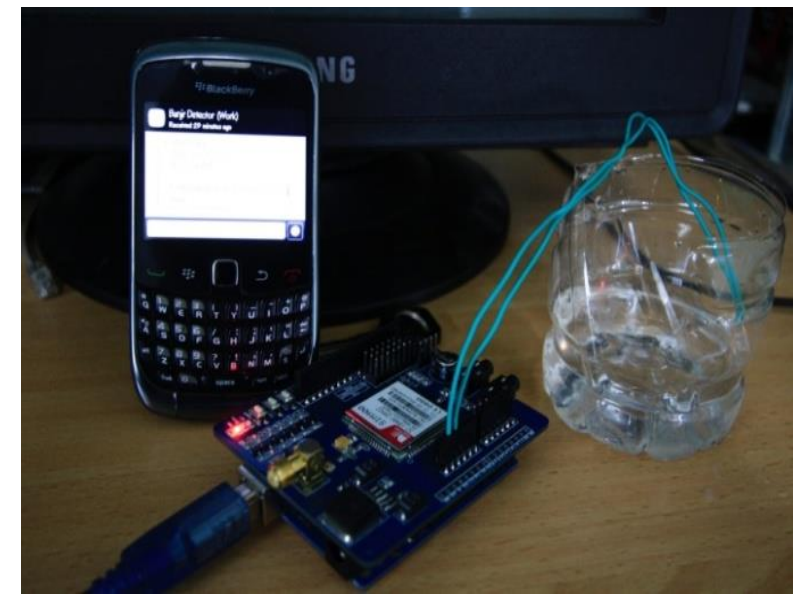

Gambar 9. Uji coba Laboratorium GSM module.

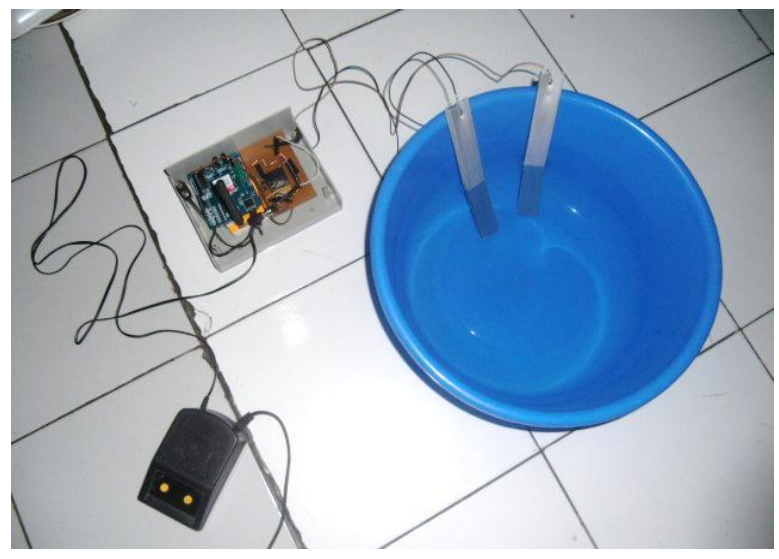

Gambar 10. Uji coba Laboratorium sistem sensor untuk peringatan melalui SMS

Uji coba awal adalah untuk menguji dan setting GSM module, seperti ditunjukkan pada Gambar 9. Selanjutnya uji coba laboratorium dilakukan dengan seperangkat sistem sensor dengan GSM shield sudah terhubung dengan rangkaian LM566 dan sensor dengan dua pelat konduktor. Adapun gambar uji coba seperti pada Gambar 10.

Tabel 3. Waktu respon sistem hasil uji coba secara langsung

\begin{tabular}{|c|c|c|}
\hline $\begin{array}{l}\text { Percobaan } \\
\text { Ke- }\end{array}$ & $\begin{array}{l}\text { Waktu } \\
\text { respon } \\
\text { SMS* }\end{array}$ & Keterangan \\
\hline 1 & 7 detik & $\begin{array}{l}\text { Uji Coba pertama } \\
\text { dilakukan di daerah }\end{array}$ \\
\hline 2 & 5 detik & $\begin{array}{l}\text { Jakarta saat kondisi tidak } \\
\text { hujan. }\end{array}$ \\
\hline 1 & 14 detik & Uji Coba dilakukan di \\
\hline 2 & 19 detik & daerah Lokasi \\
\hline 3 & 20 detik & $\begin{array}{l}\text { pengabdian masyarakat, } \\
\text { saat kondisi tidak hujan. }\end{array}$ \\
\hline
\end{tabular}




\begin{tabular}{|c|c|c|}
\hline 4 & 35 detik & Uji Coba dilakukan di \\
\hline & 53 detik & $\begin{array}{l}\text { Lokasi } \\
\text { lian mas }\end{array}$ \\
\hline & 59 detik & saat kondisi hujan. \\
\hline
\end{tabular}

Uji coba selanjutnya adalah penerapan sistem sensor di lokasi pengabdian masyarakat. Gambar 11 adalah gambar perangkat sistem sensor yang dipasang dilokasi pengabdian masyarakat, daerah Bekasi. Untuk pengujian secara langsung dilokasi pengabdian masyarakat, akan diuji dan dicari lama waktu respon sistem, yakni mulai dari air menyentuh sensor pelat konduktor sampai diterimanya SMS. Berdasarkan hasil uji coba, diperoleh data waktu respon sistem seperti pada Tabel 3.

Dari hasil percobaan pada tabel diatas, waktu respon pengiriman SMS (mulai dari sensor menyentuh air dan mengaktifkan perangkat GSM modul dan sampai SMS diterima), diperoleh hasil yang cukup berbeda saat kondisi baik (tidak hujan) dengan saat terjadi hujan lebat dan berangin. Keterlambatan respon dapat dikarenakan kondisi cuaca (noise) yang mempengaruhi pengiriman SMS oleh operator GSM yang digunakan.

Berdasarkan hasil uji coba di derah pengabdian masyarakat, dapat dianalisa hasil percobaan bahwa sistem sensor air menggunakan dua pelat konduktor telah berhasil memberikan isyarat ketinggian air. Sistem Sensor dan Rangkaian Relay LM339 bekerja dengan baik, dengan waktu respon yang cepat yakni < 1 detik. Waktu respon pengiriman SMS mulai dari sensor menyentuh air sampai SMS diterima adalah rata-rata 17 detik pada saat kondisi hujan dan rata-rata 49 detik pada saat hujan. Adapun ringkasan hasil uji coba rancangan sistem tertera pada Tabel 4 berikut:

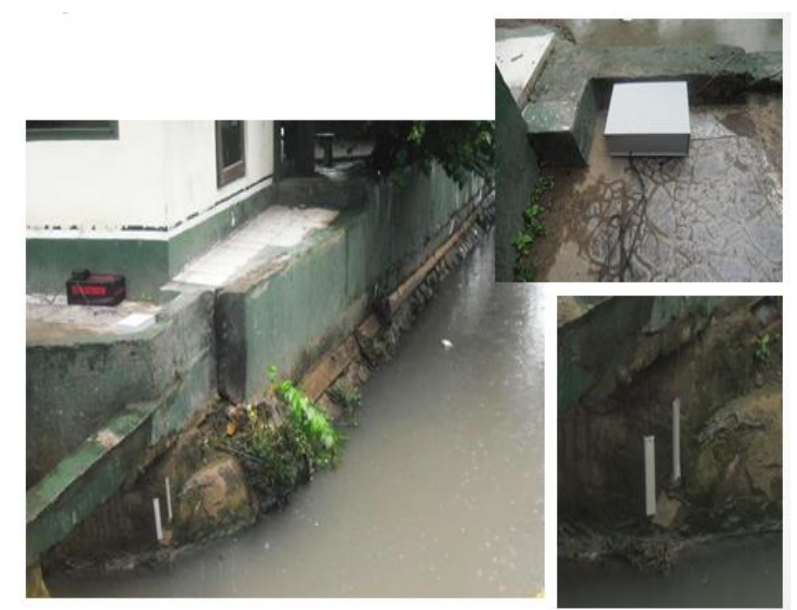

Gambar 11. Uji coba di lokasi pengabdian masyarakat.
Tabel 4. Hasil analisa uji coba secara langsung

\begin{tabular}{|c|c|}
\hline Sistem & Hasil Uji Coba \\
\hline Sensor Air & $\begin{array}{l}\text { Berhasil } \\
\text { (dengan Pelat Aluminium dan } \\
\text { Pelat Besi) }\end{array}$ \\
\hline $\begin{array}{l}\text { Rangkaian Relay } \\
\text { LM339 }\end{array}$ & $\begin{array}{l}\text { Berhasil } \\
\text { Waktu Respon mulai dari sensor } \\
\text { menyentuh air sampai Relay } \\
\text { berbunyi/LED indikator } \\
\text { menyala: < } 1 \text { detik. }\end{array}$ \\
\hline $\begin{array}{l}\text { Microcontroller } \\
\text { dan GSM Modul }\end{array}$ & $\begin{array}{l}\text { Waktu Respon pengiriman SMS } \\
\text { mulai dari sensor menyentuh } \\
\text { air: } \\
\text { Uji coba I: + } 6 \text { detik. } \\
\text { Uji coba II: } \\
\quad+17 \text { detik } \\
\text { + } 49 \text { detik (saat kondisi hujan). }\end{array}$ \\
\hline
\end{tabular}

\section{KESIMPULAN}

Dari hasil uji coba di laboratorium untuk sistem sensor air dengan prinsip dasar bahwa air sebagai penghantar menggunakan dua pelat konduktor telah berhasil memberikan isyarat ketinggian air. Untuk hasil uji coba sistem microcontroller dan GSM Module juga telah berhasil mengirimkan SMS (alert banjir) dalam waktu \pm 49 detik

\section{DAFTAR PUSTAKA}

[1]. S. Syukri, "Kimia Dasar 2," Bandung, ITB, 1999, pp. 378-387.

[2]. Era Kurniasari P. F, Yose Rizal. Rancang Bangun Kontrol Otomatis Pompa Pematusan dan Pintu Air Berbasis PLC untuk Mengatasi Banjir. Tugas Akhir. 2010.

[3]. SMS Warning Ketinggian Permukaan Air. http://SMS WARNING Ketinggian Permukaan Air_SHATOMEDIA ONLINE.htm. Juli 2010.

[4]. Tegar Bhakti Prihantoro, Rizky Charli Wijaya Husni. Alat Pendeteksi Tinggi Permukaan Air Secara Otomatis Pada Bak Penampungan Air Mengunakan Sensor Ultrasonik Berbasis Mikrokontroler. Tugas Akhir. 2010.

[5]. Amelia Syarfina Qisthi, Ajub Ajulian. Perancangan Pendeteksi Banjir Jarak Jauh Menggunakan Sistem Komunikasi 802.15.4. Makalah Seminar Kerja Praktek.

[6]. Zohri, Muhamad. Pengukur Ketinggian Air Berbasis Mikrokontroler AT89C51 Melalui SMS. Skripsi. Jurusan Fisika. Fakultas Sains dan 
Teknologi. Universitas Islam Negeri (UIN) Malang. 2009.

[7]. DKI Terus Sempurnakan Sistem Peringatan Dini Banjir (7 Desember 2012). http://www.investor. co.id/cosmopolitan/dki-terus-sempurnakan-sistemperingatan-dini-banjir/50334.

[8]. Ma'rifin Ardiansyah, Taufiqurrahman, Wahyoe Tjatur Sesulihatien. Sistem Informasi Bencana Banjir (Akusisi Data Multiple Sensor). The $13^{\text {th }}$ Industrial Electronics Seminar (IES) 2011.
[9]. Suprapto. Alat Pemantau Level Air Sistem Terpusat Manfaatkan Sms Sebagai Media Pengirim Data. Jurnal TIF, Vol. 1 No. 1. 2010.

[10]. P. Pratama, Pranedya. Tugas Akhir: Perancangan Perangkat Sistem Pengendali keamanan Pintu Rumah Berbasis Pesan singkat (SMS) Menggunakan miikrokontroler Atmega8535, Tugas Akhir: Universitas Diponegoro. 